\title{
Review: haloperidol does not reduce agitation in dementia
}

Lonergan E, Luxenberg J, Colford J. Haloperidol for agitation in dementia. Cochrane Database Syst Rev 2001(4):CD002852

(latest version 28 Aug 2001).

\section{QUESTION: In patients with dementia, is haloperidol effective for decreasing agitation?}

\section{Data sources}

Studies were identified by searching the Specialized Register of the Cochrane Dementia and Cognitive Improvement Group, which contains records from 15 databases. Pharmaceutical companies and authors were contacted.

\section{Study selection}

2 reviewers independently selected studies in any language if they were randomised, placebo controlled trials with allocation concealment and assessment of agitation before and after treatment; if they involved patients who had dementia (unclassified or diagnosed according to criteria) and agitation and treatable causes were ruled out; and if they evaluated haloperidol for $>1$ week.

\section{Data extraction}

Reviewers assessed the quality of studies and extracted data on patient and study characteristics, interventions, and outcomes (the main outcome was decrease in manifestations of agitation).

\section{Main results}

5 studies (876 patients, mean age range 72 to 82 y, $56 \%$ to $67 \%$ women) met the selection criteria. 3 studies included outpatients, and 2 studies included institutionalised patients. Treatment duration ranged from 3 to 16 weeks (mean 8.6 wks). Mean doses were categorised as $<2 \mathrm{mg} /$ day and $>2 \mathrm{mg} /$ day (range 0.5 to $6.0 \mathrm{mg} / \mathrm{d}$ ). In patients with mild or moderate dementia (MiniMental State Examination score 12 to 19), the groups did not differ for agitation or global improvement (table) on any type of measure or dose. Haloperidol, mean dose $>2 \mathrm{mg} /$ day, led to a greater reduction in aggression (2 studies, standardised mean difference in change from baseline score 0.37 , 95\% CI 0.11 to 0.62 ) and to more patients with $\geqslant 1$ extrapyramidal symptom or who dropped out because of adverse events by 3 to 6 weeks (1 study) (table) than did placebo. No difference was seen for akathisia or Parkinsonian gait. For patients with severe dementia, haloperidol, mean dose $<2 \mathrm{mg}$ /day, led to a greater reduction in aggression than did placebo (1 study, mean difference in change from baseline score on the Behavior Pathology in Alzheimer's Disease Rating Scale-aggression subscale 0.88, CI 0.12 to 1.64).

\section{Conclusion}

In patients with dementia, haloperidol reduces aggression but does not reduce agitation and increases some adverse events.
Source of funding: not stated.

For correspondence: Dr E Lonergan, VA Medical Center, San Francisco, California, USA.

tedlnrgn@aol.com or edmund.lonergan@ med.va.gov.

\section{COMMENTARY}

The review by Lonergan $e t$ al is a valiant attempt to draw some useful conclusions from a disparate group of studies of haloperidol in dementia. Only 5 studies could be included, which amounted to $<300$ patients on active treatment. Because of a plethora of outcome variables, the subanalyses reduced the numbers even more. An adequate placebo controlled study of haloperidol may no longer be ethical, so gleaning what little information we can from available data has some merit. The authors conclude that haloperidol has some benefit in aggression rather than in the blanket area of agitation. This conclusion suggests that the antipsychotic effect may reduce symptoms secondary to the psychotic experience rather than through any non-specific sedation. However, such side effects as motor restlessness may have confounded any reductions in psychotic symptoms because agitation may have appeared to have worsened.

The Cohen and Mansfield Agitation Inventory has some acceptance as a standard measure but was used in only 3 studies, 1 of which had only 6 patients receiving haloperidol. Many of the other scales used were reduced to subscales of hallucinations and delusions as a proxy for agitation. The chosen studies excluded delirium, which is an area of interest because antipsychotics are often used while the underlying pathological condition is treated.

This overview, besides highlighting the inadequacy of studies in this area, suggests that antipsychotics may not be a useful symptomatic treatment in dementia. Haloperidol may be less clinically relevant since the advent of atypical antipsychotics. For example, the National Service Framework for Older People in the UK suggests that atypical antipsychotics may cause fewer adverse effects.

Cholinesterase inhibitors as a class show considerable promise in studies where noncognitive symptoms of Alzheimer's disease have been assessed and offer a more rational treatment than antipsychotic drugs. ${ }^{2}{ }^{3}$

$$
\begin{array}{r}
\text { David Wilkinson, MD } \\
\text { Moorgreen Hospital, University of Southampton } \\
\text { Southampton, UK }
\end{array}
$$

1 National Service Framework for Older People. London: Department of Health, 2001:105 (Standard 7:7.41) (http://www.doh.gov.uk/nsf).

2 McKeith I, Del Ser T, Spano P, et al. Efficacy of rivastigmine in dementia with Lewy bodies: a randomised, double-blind, placebo-controlled international study. Lancet 2000;356:2031-6.

3 Feldman H, Gauthier S, Hecker J, et al. A 24-week, randomized, double-blind study of

\begin{tabular}{|c|c|c|c|c|c|}
\hline Outcomes & Dose & Hal & Placebo & $\mathrm{RBI}(95 \% \mathrm{Cl})$ & NNT \\
\hline CGIC improvement at 3 to 4 weeks & $>2 \mathrm{mg} / \mathrm{day}$ & $79 \%$ & $69 \%$ & $15 \%(-2.4$ to 36$)$ & Not significant \\
\hline \multirow[t]{2}{*}{ CGIC improvement at 16 weeks } & $<2 \mathrm{mg} /$ day & $32 \%$ & $31 \%$ & $5.9 \%(-47$ to 110$)$ & Not significant \\
\hline & & & & RRI (Cl) & NNH (Cl) \\
\hline Drop outs because of adverse events by 3 to 6 weeks & $>2 \mathrm{mg} / \mathrm{day}$ & $17 \%$ & $5.8 \%$ & $189 \%(23$ to 589$)$ & $10(5$ to 41$)$ \\
\hline$\geqslant 1$ extrapyramidal symptom by 3 to 6 weeks & $>2 \mathrm{mg} /$ day & $34 \%$ & $17 \%$ & $93 \%(18$ to 219$)$ & 7 (4 to 24$)$ \\
\hline
\end{tabular}
donepezil in moderate to severe Alzheimer's disease. Neurology 2001;57:613-20.

Haloperidol (Hal) v placebo for moderate or mild dementia*

${ }^{*} \mathrm{CGIC}=$ Clinical Global Impression of Change. Other abbreviations defined in glossary; RBI, RRI, NNT, NNH, and Cl calculated from data in article. 